Gut, 1989, 30, 1721-1730

\title{
Gut hormone responses after reconstructive surgery for ulcerative colitis
}

\author{
G R GREENBERG, A M J BUCHAN, R S MCLEOD, P PRESTON, \\ AND Z COHEN \\ From the Departments of Medicine and Surgery, University of Toronto, Toronto, and Department of \\ Physiology, University of British Columbia, Vancouver, Canada
}

Summary After colectomy, continent ileal reservoirs are an accepted alternative to conventional ileostomy for patients with ulcerative colitis. To assess the effect of these reservoirs on digestive function, circulating and morphologic gut endocrine responses were measured in patients with a continent ileostomy or with a pelvic pouch and compared to patients with conventional ileostomy, with active ulcerative colitis and healthy controls. Eight subjects were studied in each group. Basal and postprandial plasma gastrin, enteroglucagon, neurotensin, vasoactive intestinal polypeptide, insulin, pancreatic glucagon, and pancreatic polypeptide in both groups with ileal reservoirs were equivalent to controls. Basal plasma motilin and postprandial plasma gastric inhibitory polypeptide were raised in ileal reservoir patients, but similar changes also occurred in ulcerative colitis patients and those with conventional ileostomy. In one half of patients, cell populations of enteroglucagon, peptide $Y Y$, and neurotensin were decreased in pouch mucosa that corresponded with the presence of mucosal inflammation. On the other hand, with pouch inflammation vasoactive intestinal polypeptide immunoreactive nerves were increased and a proportion of the fibres were moderately coarsened. Mucosal concentrations of vasoactive intestinal polypeptide did not, however, exceed that of controls. After an ileal reservoir sufficient reserve remains for gut hormone release into the circulation, suggesting compensation for the presence of a reservoir and the absence of a colon; circulating hormone changes do occur but are consequent upon previous ulcerative colitis. Reservoirs may show neuromorphologic alterations that appear to be related to mucosal inflammation.

Recent advances in the surgical management of ulcerative colitis now give patients who require colectomy the option of having intestinal continence restored. Although two different surgical techniques have been developed to achieve this goal, both share the common feature of creating a permanent internal pouch from distal ileum. In the first procedure, the continent ileostomy or Koch pouch, an abdominal small bowel reservoir and nipple valve is constructed from $45 \mathrm{~cm}$ ileum, primarily for patients who have previously undergone proctocolectomy.' Stool is emptied from the pouch at regular intervals by catheter intubation. Alternatively, in the second procedure, the pelvic pouch, all but a few centimetres of colon is removed and a mucosal proctectomy or

Address for correspondence: Dr G R Greenterg, 6356, Medical Sciences BIdg. University of Toronto, Toronto. Ontario, Canada M5S $1 \mathrm{~A} 8$.

Accepted for publication 4 April 1989 stripping of the remaining rectal mucosa is undertaken. ${ }^{2}$ A small bowel pouch is then constructed in the pelvis and the distal end anastomosed to the anus, thus maintaining intestinal continuity. Both procedures eliminate the need for an appliance and after several surgical modifications, complication rates are acceptably low and patient satisfaction generally high."

Notwithstanding these encouraging clinical results, up to half of patients may develop within the ileal reservoir, histological abnormalities that include chronic inflammation with subtotal villous atrophy. ${ }^{+}$ Similar changes in the proximal intestine, as for example in coeliac disease, cause several abnormalities in digestive functions, partly because of alterations in gastrointestinal hormone release. ${ }^{5}$ In the ileum and colon, many of the gut hormones also play integral roles in the regulation of secretory, motor, 
metabolic and trophic functions of the gut, yet the possible effects of an ileal reservoir, with or without inflammation, on gut hormone profiles are unknown.

Therefore, in the present study, the circulating gut hormone responses to a standardised meal were determined in patients who had undergone one of the two types of ileal reservoir procedures. To ensure that differences would not be consequent upon the absence of a colon or previous active colonic inflammation, patients with conventional ileostomy and those with active ulcerative colitis were also studied. In addition, the immunocytochemical distribution and concentrations of gut peptides, that included vasoactive intestinal peptide, were assessed on mucosal biopsies obtained from ileal reservoirs. The particular interest in vasoactive intestinal polypeptide stems from observations that a subgroup of ileal reservoir patients develop acute ulceration of unknown aetiology within the pouch (pouchitis) and coarsening of nerve fibres containing vasoactive intestinal polypeptide has been described in abnormal intestine of other idiopathic inflammatory bowel diseases, notably Crohn's disease. ${ }^{n}$

\section{Methods}

\section{SUBJECTS}

Five groups each comprised of eight subjects participated in the meal study. Included were patients with (i) active ulcerative colitis in whom pancolitis was diagnosed by endoscopy and histology, (ii) a conventional ileostomy, (iii) a continent ileostomy or Koch pouch constructed from $45 \mathrm{~cm}$ ileum, (iv) a pelvic pouch of the J-shape type constructed from $40 \mathrm{~cm}$ ileum, and (v) healthy control subjects without a previous history of gastrointestinal disease. All 24 postoperative patients had undergone colectomy for pathologically proven ulcerative colitis and studies were performed at least three months after their last abdominal operation. None had had a previous small bowel resection. Before the meal study all medications were discontinued with the exception of prednisone (mean daily dose of $25 \mathrm{mg}$ ) in the group with active ulcerative colitis. Table 1 summarises the clinical features of each patient group.
On separate occasions endoscopic evaluation and biopsies were obtained in 27 patients with either a Koch pouch or pelvic pouch, 15 of whom had also undergone test meal studies. The patients were categorised as to whether the pouch was normal endoscopically and on conventional histology (Koch pouch $n=6$; pelvic pouch $n=9$ ) or whether there was endoscopic and histological pouchitis (Koch pouch $\mathrm{n}=6$; pelvic pouch $\mathrm{n}=6$ ). In those patients who also had participated in the test meal study pouchitis was identified in three patients with a Koch pouch and four patients with a pelvic pouch. For comparison, mucosal biopsies were taken at the time of colonoscopy from the terminal ileum of six patients without intestinal inflammation. These paticnts had either carcinoma of the colon or a colonic adenomatous polyp. The research protocols were approved by the Human Experimentation Committec, University of Toronto on 15 July 1982 and informed consent was obtained from each subject.

\section{DESIGN}

All subjects fasted overnight and then ingested a palatable standardised test breakfast composed of orange juice, two eggs, toast and jam ( $18 \mathrm{~g}$ protein, $22 \mathrm{~g}$ fat, $66 \mathrm{~g}$ carbohydrate, 530 calories). During each meal study, blood samples were taken at -30 , $-15,0,15,30,45,60,90,120,150$, and $180 \mathrm{~min}$ through an indwelling catheter placed in an antecubital vein. All blood samples were taken into tubes containing $500 \mathrm{KIU}$ of aprotinin (Trasylol, FBA Pharmaceuticals, Pointe Claire, Quebec, Canada) per $\mathrm{ml}$ of blood and $10 \mathrm{U}$ heparin, immediately centrifuged and the plasma deep frozen at $-20^{\circ} \mathrm{C}$ until hormone determinations were performed.

Biopsy samples were taken through an Olympus CFP $10 \mathrm{~L}$ colonoscope with FB-24U biopsy forceps. Two biopsies were placed in Bouin's solution for a period not exceeding $90 \mathrm{~min}$ and then transferred to absolute ethanol until processed for morphological analysis. Two further biopsies were weighed and placed in $0.5 \mathrm{ml} 0.5 \mathrm{M}$ acetic acid for extraction and subsequent determination of protein and hormone concentrations.

Table 1 Clinical features of patient groups*

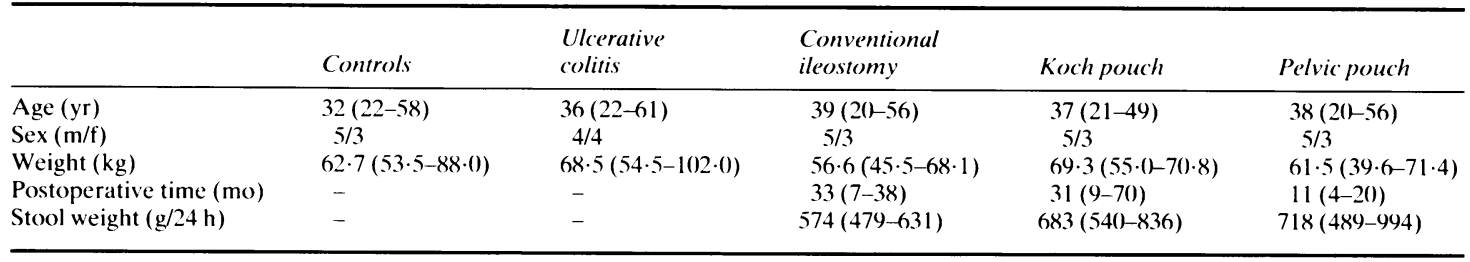

*Values given are mean and range. 
LABORATORY PROCEDURES

Blood glucose was measured by the glucose oxidase method using standard automated techniques (Beckman glucose analyser method II). Plasma hormone concentrations were measured by specific radioimmunoassays described in detail previously for gastrin, ${ }^{7}$ motilin, ${ }^{8}$ gastric inhibitory polypeptide, ${ }^{9}$ insulin," pancreatic glucagon," pancreatic polypeptide," vasoactive intestinal polypeptide," and enteroglucagon." The vasoactive intestinal polypeptide antiserum, V-9, is directed more towards the central sequence of vasoactive intestinal polypeptide but reacts with the whole molecule." Plasma enteroglucagon (glucagon-like immunoreactivity of intestinal origin) was derived by subtraction of values obtained using an antibody (RCS5) specific for pancreatic glucagon" from values obtained using antibody K4023 (Novo Research Institute, Copenhagen, Denmark) which has been shown to give linear dilution curves with crude pork gut glucagonlike immunoreactants and with purified gut glucagon-like immunoreactants. ${ }^{12}$ The values are expressed as equivalents of glucagon. Neurotensin was measured by radioimmunoassay following the methods of Blackburn and Bloom ${ }^{13}$ using a C-terminal directed antibody (Cambridge Research Biochemicals Ltd, New York, New York) at a final dilution of 1:45000. Synthetic neurotensin was iodinated by the lactoperoxide technique and the ['25I]-labelled tracer was purified by gel permeation chromotography to a specific activity of $1.7 \mathrm{nCi} / \mathrm{fmol}$. The assays were capable of detecting the following plasma changes with $95 \%$ confidence: gastrin $2 \mathrm{pmol} / \mathrm{l}$, gastric inhibitory polypeptide $3 \mathrm{pmol} / \mathrm{l}$, motilin $3 \mathrm{pmol} / \mathrm{l}$, pancreatic polypeptide $2 \mathrm{pmol} / \mathrm{l}$, insulin $5 \mathrm{pmol} / \mathrm{l}$, pancreatic glucagon $2 \mathrm{pmol} / \mathrm{l}$, enteroglucagon $5 \mathrm{pmol} / \mathrm{l}$, neurotensin $4 \mathrm{pmol} / \mathrm{l}$, and vasoactive intestinal polypeptide $2 \mathrm{pmol} / \mathrm{l}$ and showed no crossreaction with each other or any of the other known hormones.

Biopsies were weighed, placed in $0.5 \mathrm{ml} 0.5 \mathrm{M}$ acetic acid and boiled in a water bath for 10 minutes. Solids were removed by centrifugation and the supernatants stored at $-20^{\circ} \mathrm{C}$ for subsequent analysis. Protein concentrations were measured on supernatant aliquots of $100 \mu \mathrm{l}$ by the Bio-Rad method (Bio-Rad, Richmond, California) with bovine serum albumin used as a standard. Vasoactive intestinal polypeptide and neurotensin were measured by radioimmunoassay on aliquots not exceeding $25 \mu \mathrm{l}$ of neat supernatant. Each sample was assayed in duplicate and at three different dilutions. Hormone concentrations are expressed as $\mathrm{pmol} / \mathrm{g}$ wet weight tissue and $\mathrm{pmol} / \mathrm{mg}$ extracted protein.

Biopsy samples for morphological analysis were dehydrated and embedded in wax. Conventional
Table 2 Characteristics of antiseralantibodies for immunocytochemistry

\begin{tabular}{|c|c|c|c|c|}
\hline Peptide & Source & Specificity & Species & Dilution \\
\hline Neurotensin & RPG & C-terminal & Mouse & $1: 100 \mathrm{tcm}$ \\
\hline VIP & RPG & $\mathrm{N}$-terminal & Mouse & Neat tcm \\
\hline Enteroglucagon & Gregor (Berlin) & N-terminal & Mouse & $1: 100 \mathrm{tcm}$ \\
\hline PYY & Polak (London) & $\mathrm{N}$-terminal & Rabbit & $1: 1000$ serum \\
\hline
\end{tabular}

RPG: regulatory peptide group; $\mathrm{tcm}$ : tissue culture supernatant.

histologic sections were stained with haematoxylineosin and mounted for assessment of inflammatory changes. For immunocytochemistry, serial $5 \mu$ sections were immunostained with antisera/antibodies (Table 2) to neurotensin, vasoactive intestinal polypeptide, enteroglucagon, and peptide $\mathrm{YY}^{14}$ localised by the biotin/avidin method. The number of immunoreactive cells $/ \mathrm{mm}$ epithelium, cell size $\left(\mu \mathrm{m}^{2}\right)$, and mucosal depth $(\mathrm{mm})$ were calculated with a videoplan/MOP (Zeiss, Canada) morphometrics system.

\section{STATISTICAL ANALYSIS}

Values are given as the mean (SEM). The postprandial integrated response for each hormone was calculated as described previously. ${ }^{9}$ Statistical significance was determined by use of Student's $t$ test for paired values to assess the significance of differences within groups for parameters with normal distribution and the Mann-Whitney U-test for parameters with a skewed distribution. Differences between groups was tested by ANOVA. When ANOVA was significant, the differences between two groups was examined by the Newman-Keuls technique. A p value of 0.05 or less was considered significant.

\section{Results}

MEAL STUDIES

Mean basal (fasting) plasma concentrations, peak postprandial rise and integrated postprandial responses for blood glucose and for each of the gut hormones measured during the meal studies are given in Table 3. Values are expressed as mean (SEM).

GASTRIN AND MOTILIN

The fasting, peak postprandial and integrated release of plasma gastrin were equivalent in both groups with continent reservoirs and not significantly different from controls (Fig. 1) or from ulcerative colitis patients and those with conventional ileostomy (Table 3). By contrast, as shown in Figure 2 basal plasma motilin concentrations in Koch and pelvic 
Table 3 Hormone release and blood glucose in patient groups

\begin{tabular}{|c|c|c|c|c|c|}
\hline & Controls & $\begin{array}{l}\text { Ulcerative } \\
\text { colitis }\end{array}$ & $\begin{array}{l}\text { Conven- } \\
\text { tional } \\
\text { ileostomy }\end{array}$ & $\begin{array}{l}\text { Koch } \\
\text { pouch }\end{array}$ & $\begin{array}{l}\text { Pelvic } \\
\text { pouch }\end{array}$ \\
\hline \multicolumn{6}{|c|}{ Gastrin } \\
\hline B & $5(1)$ & $10(2)$ & $8(3)$ & $8(1)$ & $9(2)$ \\
\hline $\mathbf{P}$ & $42(7)$ & $40(6)$ & $54(13)$ & $39(5)$ & $49(13)$ \\
\hline IR & $4 \cdot 5(0 \cdot 9)$ & $3.9(0 \cdot 5)$ & $5 \cdot 0(1 \cdot 2)$ & $3 \cdot 9(0 \cdot 7)$ & $5 \cdot 1(1 \cdot 5)$ \\
\hline \multicolumn{6}{|c|}{ Motilin } \\
\hline B & $35(7)$ & $89(18) \dagger$ & $92(17) \dagger$ & $103(25) \dagger$ & $90(18) \dagger$ \\
\hline $\mathbf{P}$ & $50(9)$ & $100(15) \dagger$ & $108(15) \dagger$ & $143(30) \dagger$ & $131(25) \dagger$ \\
\hline IR & $-1 \cdot 3(0 \cdot 7)$ & $-3 \cdot 4(1 \cdot 6)$ & $-2 \cdot 7(1.9)$ & $-1 \cdot 0(1 \cdot 6)$ & $-1.9(1 \cdot 8)$ \\
\hline \multicolumn{6}{|c|}{ GIP } \\
\hline B & $15(3)$ & $16(3)$ & $17(4)$ & $12(5)$ & $12(3)$ \\
\hline $\mathbf{P}$ & $40(2)$ & $79(7) \ddagger$ & $66(9) \dagger$ & $86(7) \ddagger$ & $71(4) \ddagger$ \\
\hline IR & $3 \cdot()(0 \cdot 4)$ & $6.9(0.9) \ddagger$ & $4.8(0.78) \dagger$ & $6.4(0.5) \ddagger$ & $6.4(0.7) \ddagger$ \\
\hline \multicolumn{6}{|c|}{ Enteroglucagon } \\
\hline B & $9(2)$ & $24(3) \ddagger$ & $15(2)$ & $16(2)$ & $16(2)$ \\
\hline $\mathbf{P}$ & $31(7)$ & $47(7) \dagger$ & $31(3)$ & $26(2)$ & $29(3)$ \\
\hline IR & $2 \cdot 3(0 \cdot 7)$ & $2 \cdot 2(0 \cdot 7)$ & $1 \cdot 7(0 \cdot 4)$ & $1 \cdot 3(0 \cdot 2)$ & $1.5(0 \cdot 4)$ \\
\hline \multicolumn{6}{|c|}{ Neurotensin } \\
\hline B & $7(2)$ & $9(2)$ & $8(2)$ & $7(1)$ & $6(1)$ \\
\hline $\mathbf{P}$ & $20(3)$ & $23(4)$ & $19(2)$ & $16(3)$ & $20(3)$ \\
\hline IR & $1 \cdot 7(0 \cdot 3)$ & $2 \cdot 2(0 \cdot 5)$ & $1 \cdot 5(0 \cdot 3)$ & $1 \cdot 4(0 \cdot 3)$ & $1 \cdot 8(0.45)$ \\
\hline \multicolumn{6}{|c|}{ Pancreatic polypeptide } \\
\hline B & $14(4)$ & $19(4)$ & $25(7)$ & $18(5)$ & $14(2)$ \\
\hline $\mathbf{P}$ & $179(30)$ & $225(33)$ & $185(26)$ & $149(18)$ & $157(24)$ \\
\hline IR & $19(4 \cdot(0)$ & $20(4 \cdot 3)$ & $20(3 \cdot 8)$ & $15(2 \cdot 3)$ & $15(2 \cdot 7)$ \\
\hline \multicolumn{6}{|c|}{ Insulin } \\
\hline B & $35(6)$ & $54(14)$ & $30(8)$ & $38(4)$ & $32(11)$ \\
\hline $\mathbf{P}$ & $551(87)$ & $575(94)$ & $465(74)$ & $511(38)$ & $496(87)$ \\
\hline IR & $46(9 \cdot 3)$ & $41(5 \cdot 6)$ & $33(5 \cdot())$ & $40(3 \cdot 1)$ & $45(9 \cdot 4)$ \\
\hline \multicolumn{6}{|c|}{ Glucose } \\
\hline B & $4 \cdot 5(0 \cdot 3)$ & $3 \cdot 9(0 \cdot 2)$ & $4 \cdot 1(0 \cdot 2)$ & $4 \cdot 4(0 \cdot 2)$ & $4 \cdot 8(0 \cdot 4)$ \\
\hline $\mathbf{P}$ & $7 \cdot 0(0 \cdot 5)$ & $7 \cdot 5(0 \cdot 9)$ & $6 \cdot 1(0 \cdot 5)$ & $7 \cdot 2(0 \cdot 2)$ & $7 \cdot 3(0 \cdot 6)$ \\
\hline IR & $113(32)$ & $280(67)^{*}$ & $100(34)$ & $196(33)$ & $193(48)$ \\
\hline
\end{tabular}

Hormone levels (B: basal; P: peak response) given as pmol/l (mean (SEM)); blood glucose concentrations given as $\mathrm{mmol} / \mathrm{l}$ (mean (SEM)). Integrated incremental response (IR) over $180 \mathrm{~min}$ with hormones as $\mathrm{nmol} / \mathrm{l}$ and glucose as $\mathrm{mol} / \mathrm{l}$ (mean (SEM)). Statistical significance versus controls: ${ }^{*} \mathrm{p}<0.05 ; \dagger \mathrm{p}<0 \cdot 01 ; \ddagger \mathrm{p}<0 \cdot(001$.

pouch patients and in conventional ileostomists and ulcerative colitis patients were significantly higher than controls ( $p<0.01$ for each patient group). After ingestion of the meal, the early rise of plasma motilin was greater in absolute terms for all patient groups but the incremental elevation and the integrated response were not different from controls (Table 3 ).

GASTRIC INHIBITORY POLYPEPTIDE, INSUIIN, AND GLUCOSE

Mean basal plasma gastric inhibitory polypeptide concentrations in all patient groups were equivalent to controls (Table 3). After the meal, a significantly greater peak postprandial rise and integrated release of plasma gastric inhibitory polypeptide occurred in

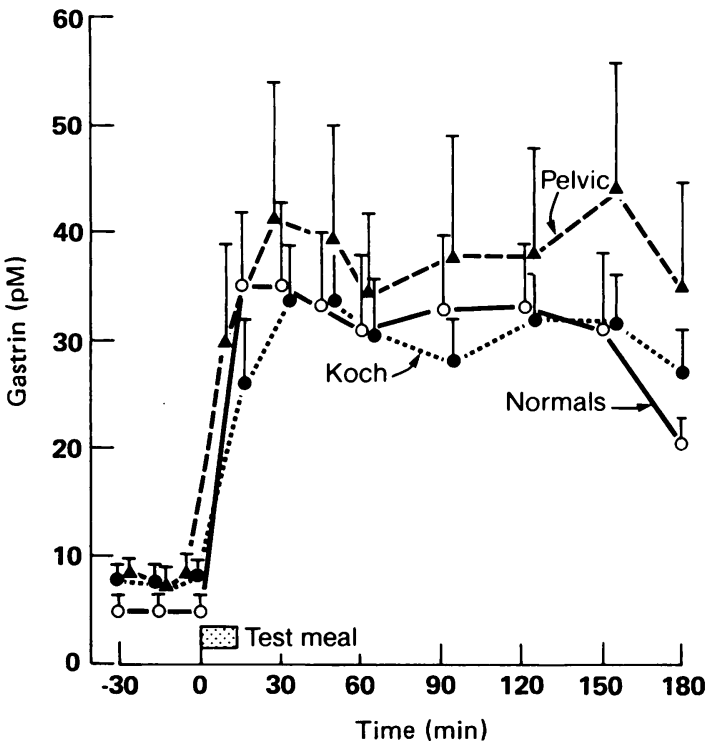

Fig. 1 Plasma gastrin response to a test meal in Koch pouch and pelvic pouch patients.

patients with a Koch pouch $(\mathrm{p}<0.001)$ or pelvic pouch $(p<0.001)$ than in control subjects (Fig. 3). Similar significant postprandial plasma gastric inhibitory polypeptide rises were observed in ulcerative colitis patients $(p<0 \cdot 001)$ and patients with a conventional ileostomy $(p<0 \cdot 001)$ compared with controls (Table 3). Notwithstanding these differences in the meal gastric inhibitory polypeptide response, fasting and postprandial rises of plasma insulin in both groups with ileal reservoirs (Fig. 4, upper panel) and in conventional ileostomists and ulcerative colitis patients (Table 3) were similar and equivalent to controls. Fasting and peak postprandial plasma glucose concentrations were also similar in all postoperative groups compared with controls (Fig. 4, lower panel and Table 3). In ulcerative colitis patients, however, the postprandial plasma glucose rise was somewhat more prolonged, and thus the integrated response was significantly greater $(p<0.05)$ than in control subjects (Table 3$)$.

ENTEROGLUCAGON AND NEUROTENSIN

Ulcerative colitis patients had significantly $(\mathrm{p}<0 \cdot 001)$ greater mean basal enteroglucagon concentrations of 24 (3) $\mathrm{pmol} / \mathrm{l}$ as compared with control subjects with values of 9 (2) pmol/l (Fig. 5). The postprandial elevation of enteroglucagon was also greater in absolute terms in ulcerative colitis patients but was proportionally similar to controls. By contrast, in both groups with an ileal reservoir (Fig. 5) and in patients with a conventional ileostomy (Table 3), 

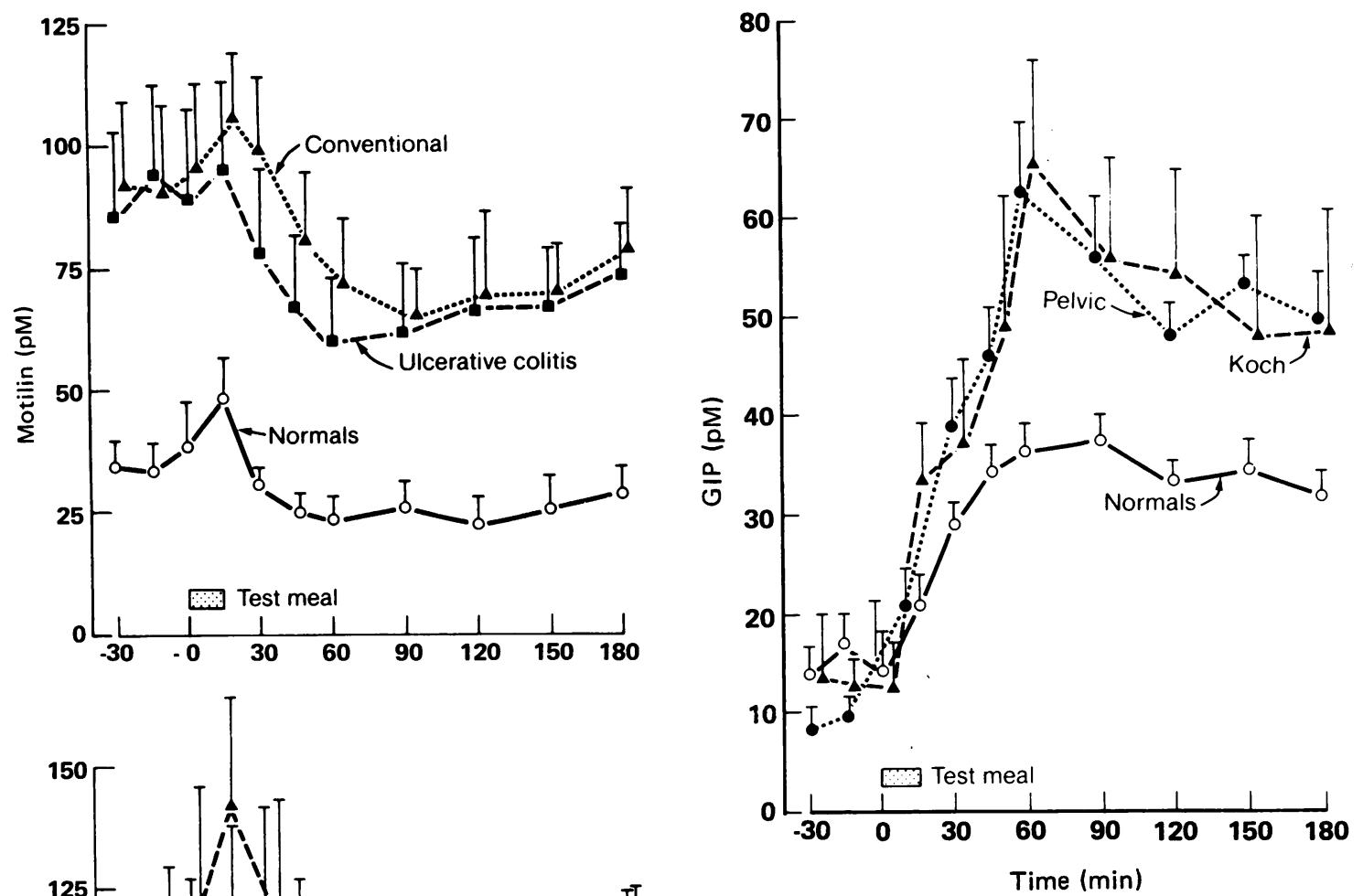

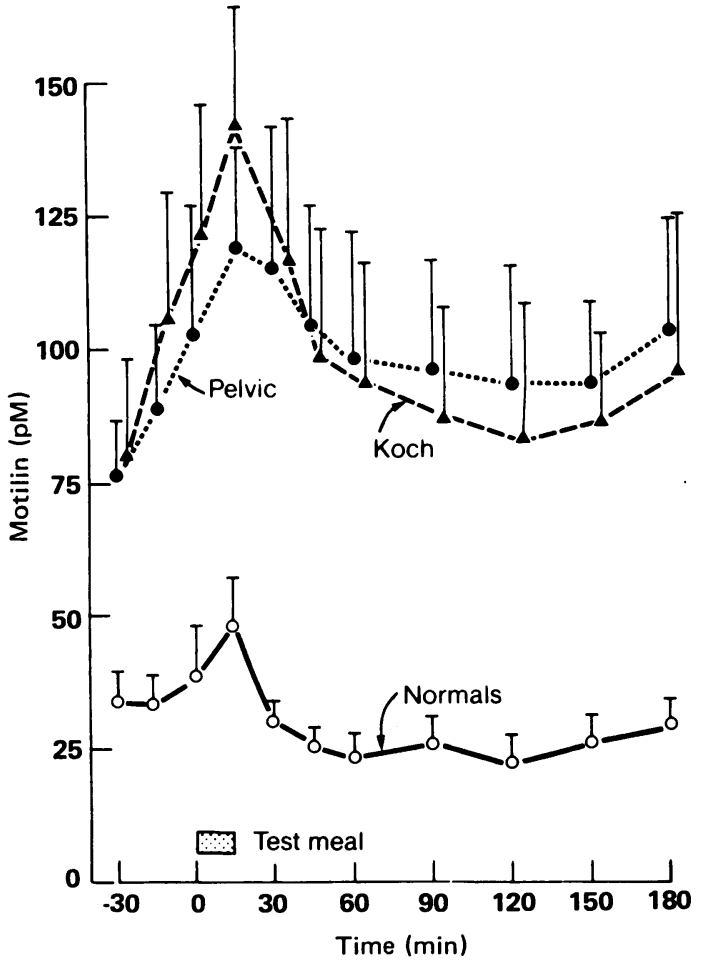

Fig. 2 Plasma motilin response to a test meal in patients with conventional ileostomy and active ulcerative colitis (upper panel) and in Koch pouch and pelvic pouch patients (lower panel).

mean basal and postprandial enteroglucagon levels were equivalent to controls. There were no signifi-
Fig. 3 Plasma gastric inhibitory polypeptide response to a test meal in Koch pouch and pelvic pouch patients.

cant differences in basal or postprandial plasma neurotensin concentrations between ulcerative colitis patients, or the postoperative groups and controls (Table 3 ).

PANCREATIC POLYPEPTIDE, PANCREATIC GLUCAGON, AND VASOACTIVE INTESTINAL POLYPEPTIDE

Fasting and postprandial plasma concentrations of pancreatic polypeptide in all patient groups did not differ significantly from those of controls (Table 3). In control subjects, basal plasma pancreatic glucagon concentrations were $5(2) \mathrm{pmol} / \mathrm{l}$ and basal vasoactive intestinal polypeptide concentrations were 4 (1) $\mathrm{pmol} / \mathrm{l}$; there was no increment of either hormone after ingestion of the meal. Equivalent values were observed for pancreatic glucagon and vasoactive intestinal polypeptide in ulcerative colitis patients and in all postoperative groups.

\section{MORPHOLOGIC STUDIES}

\section{Immunohistochemistry}

Continent reservoir patients with pouchitis irrespective of origin (Koch pouch or pelvic pouch) showed a 

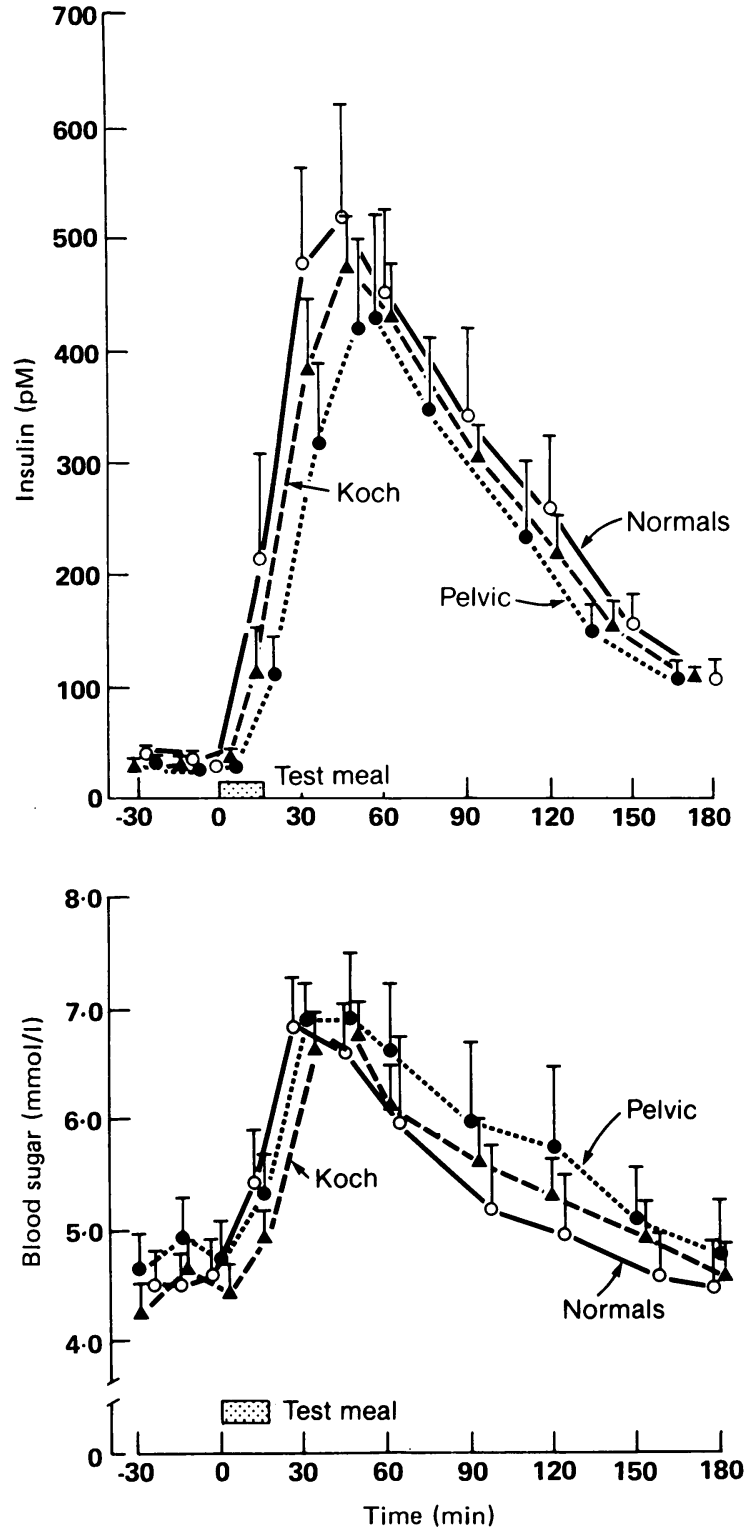

Fig. 4 Plasma insulin (upper panel), and plasma glucose (lower panel) responses to a test meal in Koch pouch and pelvic pouch patients.

significant decrease in the number and size of enteroglucagon, neurotensin, and peptide $\mathrm{YY}$ cell types (Fig. 6, Table 4). By contrast, there was a moderate increase in vasoactive intestinal polypeptide immunoreactive nerve fibres associated with the epithelium and a proportion of these nerve fibres were notably coarse (Fig. 7). The mucosal biopsies

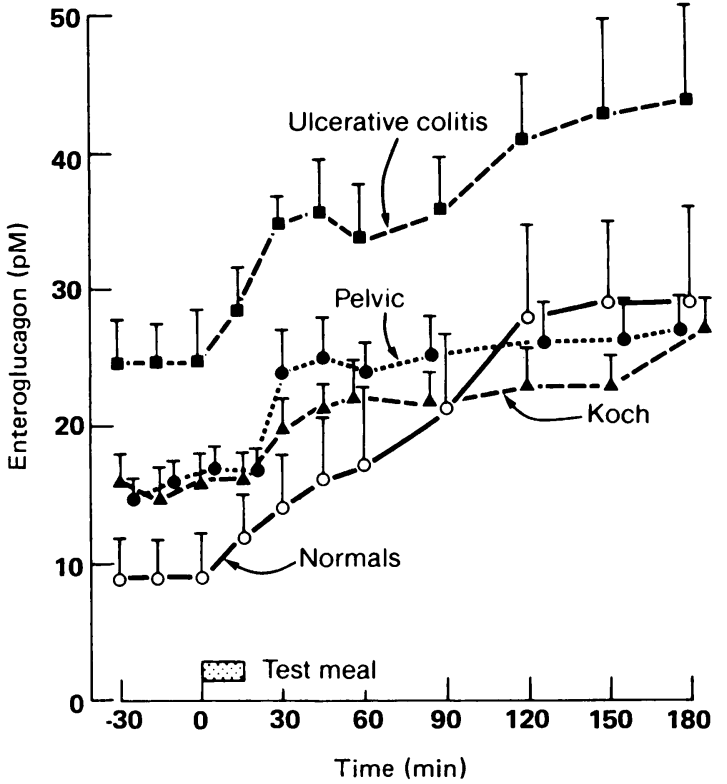

Fig. 5 Plasma enteroglucagon response to a test meal in patients with a Koch pouch, patients with a pelvic pouch and active ulcerative colitis patients.

from pouchitis patients also showed sub-total villous atrophy and crypt hypertrophy (Table 4). In ileal reservoir patients without pouchitis, there was no significant difference in any of the parameters measured, all of which were similar to control subjects (Table 4).

\section{Tissue content}

The concentration of vasoactive intestinal polypeptide in both pouch groups with normal endoscopy and conventional histology was equivalent to that in control patients with a normal terminal ileum (Table 5). In both groups of pouchitis patients, the mucosal vasoactive intestinal polypeptide concentrations tended to be lower than controls but the difference was significant $(p<0 \cdot 05)$ only in patients with a pelvic pouch (Table 5). Mucosal concentrations of neurotensin were equivalent in pouchitis patients and normal pouch patients and the values did not differ from those of controls (Table 5). The concentration of extractable protein in the mucosa of patients with pouchitis did not differ from that of the control group or of patients with normal pouches.

\section{Discussion}

The present study has showed that after construction of a continent ileal reservoir, basal levels and the postprandial release of several hormones found in 


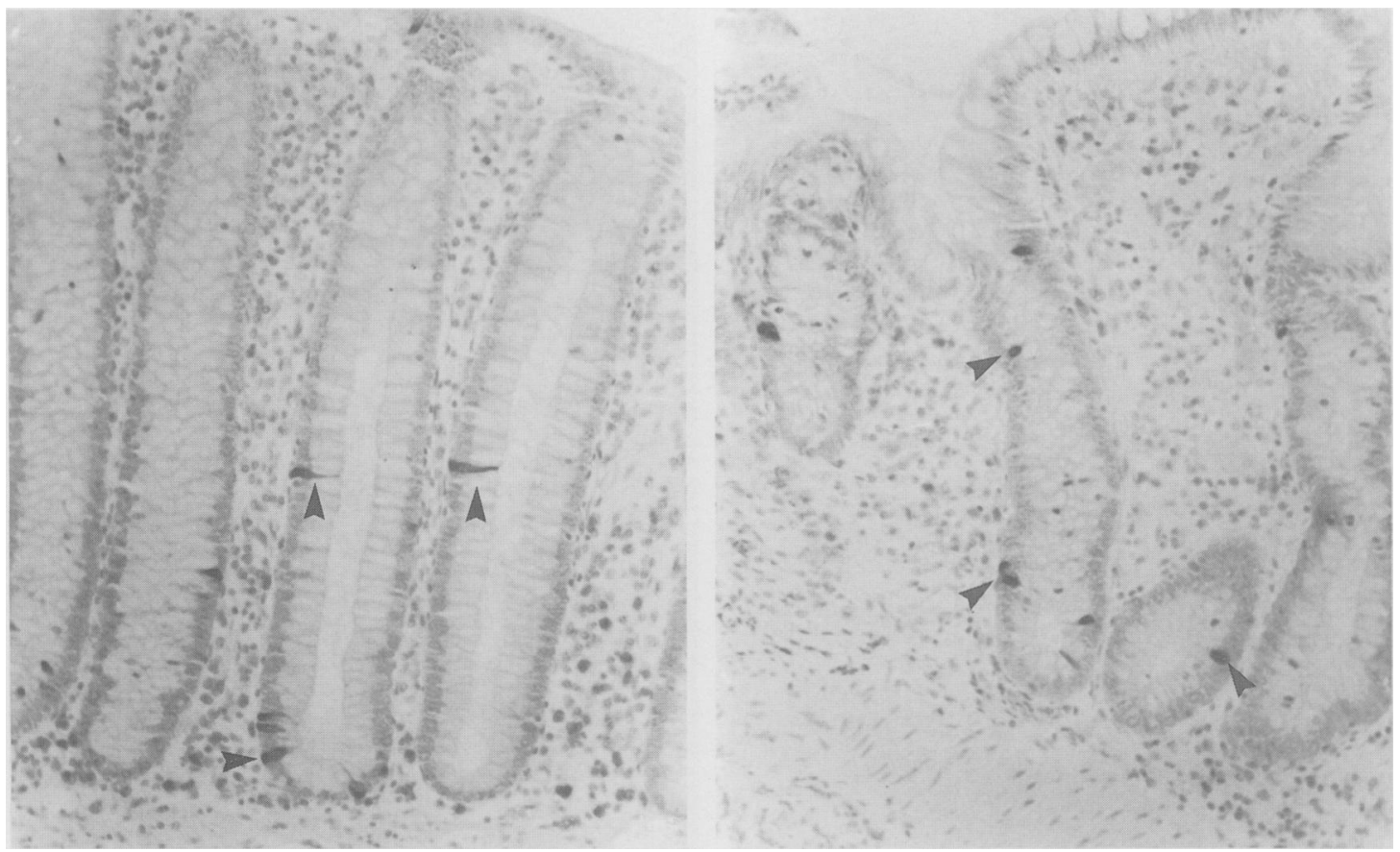

Fig. 6 Left: A normal Koch pouch stained with antibodies to enteroglucagon localised by the avidin-biotin peroxidase method and counterstained with haematoxylin. Note the size of the enteroglucagon-containing cells (arrows). The cells run through the epithelium from the lumen to basement membrane. Right: A similar section from a Koch pouch with pouchitis. Note the smaller size of the enteroglucagon cells (arrows).

different regions of the gut and pancreas are comparable with those of healthy subjects. There were, however, certain exceptions that unexpectedly occurred in the profiles of two upper gastrointestinal hormones.

Basal and postprandial plasma motilin levels were significantly increased in patients with both types of continent reservoir. Notably, similar rises were observed not only in the conventional ileostomy group but also in patients with active ulcerative colitis. These latter findings confirm previous observations on motilin profiles by Besterman et al ${ }^{15}$ in ulcerative colitis patients and by Kennedy $e t a l^{10}$ in subjects with an ileostomy. Raised plasma motilin concentrations therefore appear to be a characteristic feature of ulcerative colitis which is not reversed either by removal of the diseased colon or by restoration of continence. This concept is supported by our preliminary studies in familial polyposis patients who have undergone an ileal reservoir where basal concentrations of plasma motilin are normal (unpublished observations). Several lines of evidence now suggest that motilin is an important peptide modulator of intestinal motor activity. Plasma concentrations of motilin cycle with, ${ }^{7}$ and can initiate, ${ }^{\mathrm{x}}$ interdigestive migrating motor complexes.

Table 4 Morphological quantification

\begin{tabular}{|c|c|c|c|c|c|}
\hline Sample & $\begin{array}{l}\text { Neurotensin } \\
\text { c/mm? }\end{array}$ & $\begin{array}{l}\text { Enteroglucagon } \\
\mathrm{c} / \mathrm{mm}^{2}\end{array}$ & $\begin{array}{l}\text { Peptide } Y Y \\
\text { c/mm }\end{array}$ & $\begin{array}{l}\text { Cell area } \\
\mu m^{2}\end{array}$ & $\begin{array}{l}\text { Mucosal depth } \\
m m\end{array}$ \\
\hline Control ileum & $22(2)$ & $29(3)$ & $23(2)$ & $11(0 \cdot 6)$ & $0 \cdot 6(0 \cdot 01)$ \\
\hline Normal Koch & $25(3)$ & $33(1)$ & $24(2)$ & $9(0 \cdot 7)$ & $0 \cdot 6(0 \cdot(02)$ \\
\hline Normal pelvic & $24(4)$ & $25(1)$ & $19(4)$ & $11(0 \cdot 4)$ & $0.5(0 \cdot() 4)$ \\
\hline Koch pouchitis & $9(2)^{*}$ & $11(1)^{\dagger}$ & $6(1)^{\dagger}$ & $6(0 \cdot 2)^{*}$ & $0.4(0.05)$ \\
\hline Pelvic pouchitis & $8(2) \dagger$ & $8(1)^{\dagger}$ & $4(1)^{\dagger}$ & $5(0 \cdot 1) t$ & $0.4(0.02)$ \\
\hline
\end{tabular}

Statistical significance versus controls: ${ }^{*} p<0.0 .5:+p<0.01$. 

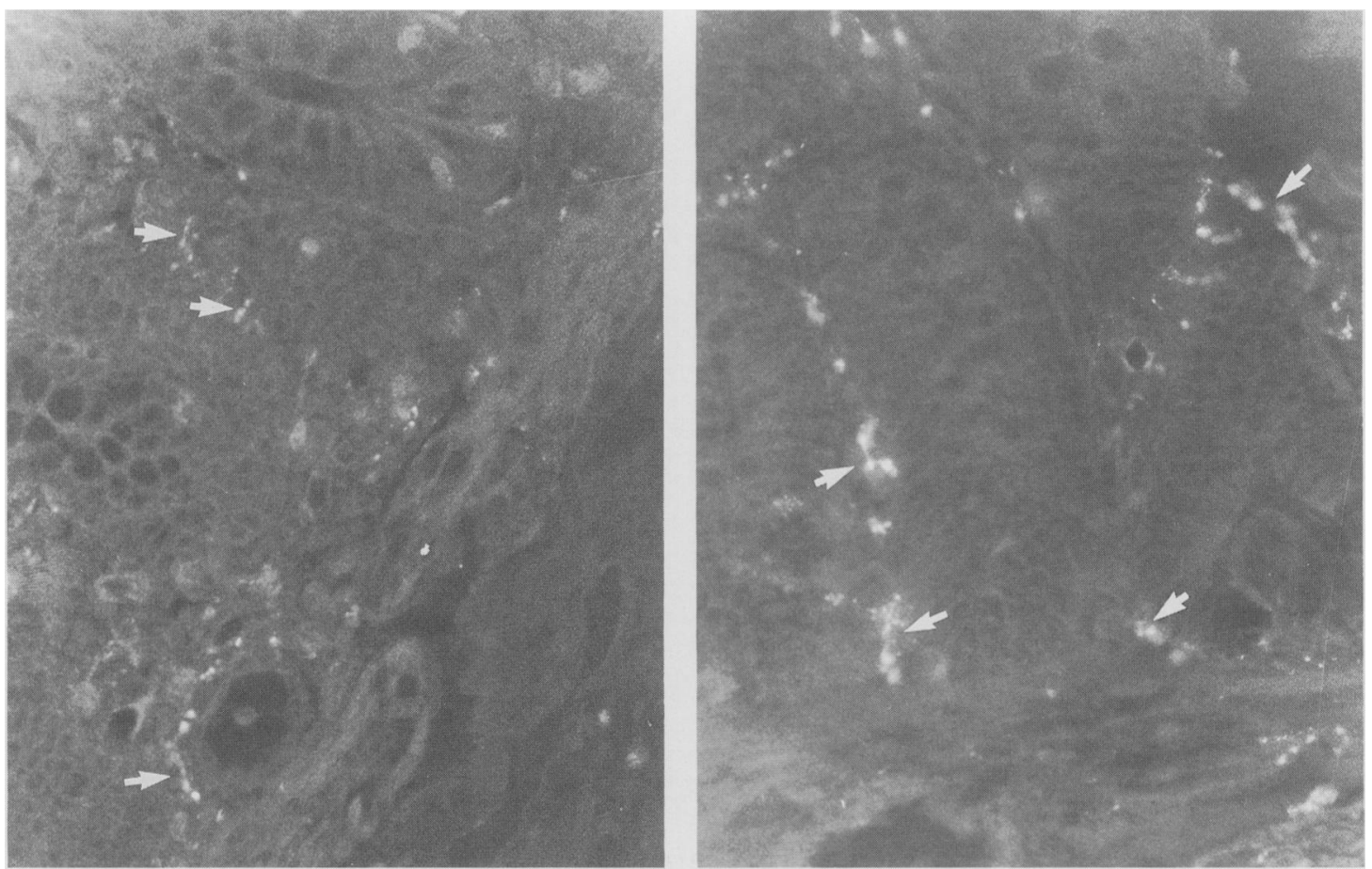

Fig. 7 Left: A normal Koch pouch stained with antibodies to vasoactive intestinal polypeptide localised by the fluorescein method. The nerve fibres around the blood vessel and in the mucosa are fine varicose fibres (arrows). Right: A similar section from a Koch pouch with pouchitis. Note that the fibres appear moderately coarsened and the varicosites larger than in the normal pouch.

Furthermore, infusions of motilin enhance gastric emptying ${ }^{17}$ and reduce small intestinal transit time. ${ }^{1 \times}$ Thus, raised plasma concentrations of motilin could contribute to the accelerated intestinal transit which has been described in both ulcerative colitis patients and in certain patients with continent reservoirs. ${ }^{\text {" }}$

Although circulating concentrations of peptide $Y Y$ were not determined in the present study, low basal plasma PYY concentrations have been recently reported in patients who have had a previous pro- tocolectomy. ${ }^{2 n} 21$ As PYY is a putative candidate for the regulation of the "ileal brake' mechanism" diminished plasma levels of PYY may operate in concert with raised plasma motilin concentrations to facilitate the enhanced intestinal motor activity observed in continent reservoir patients.

Whereas basal and postprandial glucose and insulin levels were normal, mean plasma gastric inhibitory polypeptide increments after ingestion of a meal were substantially greater in ileal reservoir

Table 5 Peptide content in mucosal biopsies

\begin{tabular}{|c|c|c|c|c|c|}
\hline & \multirow[b]{2}{*}{ Controls } & \multicolumn{2}{|l|}{ Koch pouch } & \multicolumn{2}{|l|}{ Pelvic pouch } \\
\hline & & Normal & Inflamed & Normal & Inflamed \\
\hline $\begin{array}{l}\text { Vasoactive intestin } \\
\mathrm{pmol} / \mathrm{mg} \text { protein } \\
\mathrm{pmol} / \mathrm{g} \text { wet weight }\end{array}$ & $\begin{array}{l}\text { de } \\
4 \cdot 4(0 \cdot 8) \\
178(32)\end{array}$ & $\begin{array}{l}2 \cdot 8(1 \cdot 1) \\
121(47)\end{array}$ & $\begin{array}{l}2 \cdot 7(0 \cdot 7) \\
117(30)\end{array}$ & $\begin{array}{c}3 \cdot 0(0 \cdot 8) \\
126(34)\end{array}$ & $\begin{array}{l}2 \cdot 2(0 \cdot 5)^{4} \\
92(20)^{*}\end{array}$ \\
\hline $\begin{array}{l}\text { Neurotensin } \\
\mathrm{pmol} / \mathrm{mg} \text { protein } \\
\mathrm{pmol} / \mathrm{g} \text { wet weight }\end{array}$ & $\begin{array}{l}0 \cdot 7(0 \cdot 2) \\
28(8)\end{array}$ & $\begin{array}{l}(0 \cdot 5(0 \cdot 2) \\
22(7)\end{array}$ & $\begin{array}{l}(0 \cdot 4(0 \cdot 1) \\
17(4)\end{array}$ & $\begin{array}{l}(1) \cdot 5(0 \cdot 2) \\
21(6)\end{array}$ & $\begin{array}{l}(1.5(0 \cdot 3) \\
21(9)\end{array}$ \\
\hline
\end{tabular}

Statistical significance versus controls: ${ }^{*} \mathrm{p}<0 .(05$. 
patients. The same magnitude of rise in postprandial gastric inhibitory polypeptide also occurred in ulcerative colitis patients, however, and we have previously noted a similar pattern of higher gastric inhibitory polypeptide responses after a meal in patients with Crohn's disease." In accord with the results of this study, Besterman et al ${ }^{15}$ also found that circulating gastric inhibitory polypeptide concentrations are greater in ulcerative colitis patients. Therefore, as with motilin, the enhanced gastric inhibitory polypeptide response we observed in ileal reservoir patients seems to be associated primarily with a history of inflammatory bowel disease. The factors that account for this finding are not entirely clear. A failure of the proposed insulin feedback on gastric inhibitory polypeptide release is unlikely because insulin levels were normal. Raised motilin concentrations might play a role since clinical settings associated with accelerated gastric emptying can result in greater plasma gastric inhibitory polypeptide responses. ${ }^{33}$ This dissociation between gastric inhibitory polypeptide and insulin levels has been observed after jejunoileal bypass ${ }^{24}$ and leads to the conclusion that incretins apart from gastric inhibitory polypeptide exist, likely located in the distal small intestine. Whether higher gastric inhibitory polypeptide concentrations in our patients reflect a compensatory rise in response to a selective reduction of an unidentified circulating incretin arising from the ileum remains to be determined. Nonetheless, our results do indicate that in ileal reservoir patients, the enteroinsular axis is well preserved without abnormalities in the enteric regulation of glycemia.

In agreement with previous studies, ${ }^{+}$histopathological assessment of mucosal biopsies taken from ileal reservoirs demonstrated abnormalities in nearly one-half of patients. The type of reservoir (Koch pouch or pelvic pouch) did not influence these findings. Although morphological reductions in enteroglucagon and neurotensin cell types were observed within inflamed pouch mucosa, basal and postprandial plasma concentrations of both peptides were normal in all of the ileal reservoir patients. Thus, there appears to be sufficient ileal reserve in distal gut hormone release that compensates for and adapts to not only the loss of a colon but also the construction of an ileal reservoir.

The pathogenesis of the acute mucosal inflammatory changes associated with pouchitis has not been entirely elucidated. A portion but not all patients respond to antibiotics, and yet there is no evidence to support the presence of a stagnant loop syndrome. ${ }^{+}$ Selected patients with pouchitis exhibit an endoscopic appearance within the reservoir that may resemble Crohn's disease and morphologic abnor- malities in VIPergic nerves that include increased numbers and fibre coarsening have been described in intestinal mucosa involved with Crohn's disease. "We have found an increase in the number of vasoactive intestinal polypeptide-immunoreactive fibres associated with the epithelium in patients with pouchitis. Although this increase was not as marked as that which occurs in patients with Crohn's disease, an additional notable feature was a moderate thickening of a proportion of the fibre bundles supplying the epithelium. The vasoactive intestinal polypeptide concentrations measured in the mucosal extracts from the pouchitis patients were, however, if anything decreased when compared with normal subjects. This discrepancy between the histologic picture and the vasoactive intestinal polypeptide tissue content has also been reported in Crohn's disease ${ }^{252}$ and might be explained by edematous mucosa associated with the inflammatory changes. The mechanisms that account for these neuromorphological changes in pouchitis are not entirely clear but probably reflect the effects of mucosal inflammation rather than any direct association with Crohn's disease.

In conclusion, basal and postprandial gut endocrine responses in patients with ileal reservoirs are well maintained. Rises in plasma motilin and gastric inhibitory polypeptide concentrations in continent reservoir patients appear to be a residual consequence of ulcerative colitis. Neuromorphologic changes do occur within ileal reservoirs of some patients that corresponds with, and are likely a nonspecific effect of, mucosal inflammation. Though gut hormones are representative of only one functional parameter, our findings suggest that the presence of a continent reservoir (and absence of a colon) do not compromise digestive functions of the gut.

This work was supported in part by a grant from the Medical Research Council of Canada (MA 6763). The authors thank J Alleyne, J Blair, and S PokolDaniel for expert technical assistance; and Professor $\mathrm{S} R$ Bloom and Dr R E Chance for the generous provision of antisera.

\section{References}

1 Koch NG. Intra-abdominal 'reservoir' in patients with permanent ileostomy. Arch Surg 1966; 99: 223-31.

2 Parks AG, Nicholls RJ, Bclliveau P. Proctocolectomy with ileal reservoir and anal anastomosis. $\mathrm{Br} J$ Surg 1980; 67: 533-8.

3 Cohen Z, McLeod RS. Stern H, Grant D. Nordgren S. The pelvic pouch and ilcoanal anastomosis procedure: surgical technique and initial results. Am J Surg 1985; 150: $601-7$.

4 Nicholls RJ, Belliveau P. Neill M. Wilks M. Tabaychali 
S. Restorative proctocolectomy with ileal reservoir: a pathophysiological assessment. Gut 1981: 22: 462-8.

5 Besterman HS. Bloom SR. Sarson DL, et al. Guthormone profile in celiac disease. Lancet 1978; i: 78.5-8.

6 Bishop AE, Polak JM, Bryant MG, Bloom SR. Hamilton S. Abnormalities of vasoactive intestinal polypeptide-containing nerves in Crohn's disease. Gastroenterology 1980; 79: 853-60).

7 Hall KE, Greenberg GR, El-Sharkaway TY, Diamant NE. Vagal control of migrating motor complex-related peaks in canine plasma motilin, pancreatic polypeptide, and gastrin. Can J Physiol Pharmacol 1983; 61: 1289-98.

8 Hall KE, Greenberg GR, El-Sharkaway TY. Diamant NE. Relationship between porcine motilin-induced migrating motor complex-like activity, vagal integrity. and endogenous motilin release in dogs. Gastroenterology 1984; 87: 76-85.

9 Greenberg GR. Wolman SL. Christofides ND. Bloom SR. Jecjecbhoy KN. Effect of total parenteral nutrition on gut hormone release in humans. Gastroenterology 1981: 80: 988-93.

10 Greenberg GR, Chan B, Nordgren S, Alleyne J. Effect of vagal blockade on food and hormone stimulated release of pancreatic polypeptide and motilin in dogs. Dig Dis Sci 1985; 30: 946-53.

11 Mitchell SJ, Bloom SR. Measurement of fasting and postprandial plasma VIP in man. Gut 1978; 19: 1043-8.

12 Heding LG. Radioimmunological determination of pancreatic and gut glucagon in plasma. Diabetologia 1971: 7: 10-9.

13 Blackburn AM. Bloom SR. A radioimmunoassay for neurotensin in human plasma. J Endocrinol 1979; 83: $175-81$.

14 Adrian TE, Ferri GL, Bacarese-Hamilton AJ, Fuessl HS. Polak JM, Bloom SR. Human distribution and release of a putative new gut hormone, peptide $\mathrm{YY}$. Gastroenterology 1985; 89: 1070-7.

15 Besterman HS, Mallinson CN. Modigliani R, et al. Gut hormones in inflammatory bowel disease. Scand $J$ Gastroenterol 1983; 18: 845-52.

16 Kennedy HJ, Sarson DL, Bloom SR, Truelove SC. Gut hormone responses in subjects with a permanent ileostomy. Digestion 1982; 24: 1.33-6.

17 Christofides ND. Modlin IM, Fitzpatrick ML, et al. Effect of motilin on the rate of gastric emptying and gut hormone release during breakfast. Gastroenterology 1979; 76: 903-7.

18 Besterman HS, Christofides ND. Welsby PD, Adrian TE, Sarson DL. Bloom SR. Gut hormones in acute diarrhoca. Gut 1983: 24: 665-71.

19 Kelly DG, Branon ME, Philips SF, Kelly KA. Diarrhoea after continent ileostomy. (jut 1980; 21: $711-6$.

20) Koch TR, Roddy DR. Go VLW. Abnormalities of fasting serum concentrations of peptide $Y Y$ in the idiopathic inflammatory bowel diseases. $A m J$ Gastroenterol 1987: 82: 321-6.

21 Adrian TE. Savage AP. Fuessl HS. Wolfe K. Besterman HS, Bloom SR. Release of peptide YY (PYY) after resection of small bowel. colon or pancreas in man. Surgery 1987: 101: 715-9.

22 Savage AP, Adrian TE, Carolan G. Chatterjec VK. Bloom SR. Effects of peptide YY (PYY) on mouth to caccum intestinal transit time and on the rate of gastric emptying in healthy volunteers. Gut 1987: 28: 166-70.

23 Creutzfeldt W, Ebert R. The enteroinsular axis. In: Go VLW, Gardner JD, Brooks FP, Lebenthal E, Di Magno EP, Scheele GA, eds. The exocrine pancreas, biology. pathobiology and diseases. New York: Raven Press, 1986: 333-46.

24 Lauritsen KB, Christensen KC. Stokholm KN. Gastric inhibitory polypeptide (GIP) release and incretin effect after oral glucose in obesity and after jejunoileal bypass. Scand J Gastroenterol 1980; 15: 489-95.

25 Koch TR, Carncy JA. Go VLW. Distribution and quantitation of gut neuropeptides in normal intestine and inflammatory bowel discase. Dig Dis Sci 1987; 32: 369-76.

26 Sjolund K. Schaffalitzky De Muckadell OB, Fahrenkrug J, Hakanson R, Peterson BG, Sundler F. Peptide-containing nerve fibres in the gut wall in Crohn's disease. Gut 1983; 24: 724-33. 